\title{
Measurement Model of Visitors' Intention to Visit Cultural Heritage Site
}

\author{
Yavana Rani.S, Muthu Kumar.N, Geetha.V
}

Purpose: This research aims to study the intention of visitors to visit cultural heritage site Rameshwaram, South India in the framework of the theory of planned behavior (TPB), by including two new factors such as past experience and tour involvement.

Approach -The primary data was done by a self-administrated survey form in Rameshwaram, a famous cultural heritage site in South India. Convenience sampling methods was used to collect quantitative data from the visitors. The sample size is 420. The data was analyzed using Structural Equation Modeling (SEM) with the statistical package Analysis of Moment Structures (AMOS).

Findings - The research result shows that Perceived control, Subjective norms, Attitude are the effective predictor constructs for visitors' intention to visit a cultural heritage site.

Research Implications - These results are prospective to help tourism stakeholders and marketers to plan suitable competitive strategies based on the tourism attractions they prefer to develop before the implementation stage.

Utility of the paper-This study promotes the application of SEM in analyzing observed data in the heritage tourism study in testing of relationships between key constructs.

Keywords- Tourists intention; cultural heritage sites; measurement model.

\section{INTRODUCTION}

India is a cultural country, globally renowned tourist destination with many exciting tourist destinations and plenty of attractions. It deserves the attention of tourists and vacationers all over the world. North India and South India are known for their large heritage tourism potential. South India is home to many historical monuments, rich culture, diverse flora and fauna, beautiful hill stations, religious sites and many more. Heritage tourism has attracted much attention in recent years. It has fostered tourism literature from a variety of perspectives, such as tourist behavior at Herbert, 2001; White, 2000), heritage attraction pricing issues (Tian et al., 2007), and heritage sites. And community development (Grimwad and Carter, 2000; Schulz, 1980), the heritage market (Nouryanti, 1996), the inflence to visit (Yan and Morrison, 2007), the visitors' perception and expectation of cultural heritage sites (Poria et al., 2006; Rojas and Camaro, 2008), and the classification of visitors in heritage cities (Espelt and Benito, 2006). The primary advantage of traditional tourism is the highly profitable tourist market segments, with sustainable growth rates.

Revised Manuscript Received on 14 September, 2019.

Yavana Rani.S, Associate Professor, CMS Business School, Jain University, Bangalore, Karnataka, India.(E-mail: s.yavanarani@gmail.com)

Muthu Kumar.N, Professor and Dean, Malla Ready College of Engineering, Hyderabad, Telangana, India.

Geetha.V, Assistant Professor, Mannar Thirumalai Naicker College, Madurai, Tamil Nadu, India. World Heritage Sites, visitor management (Johnson, 1999;

The purpose of this study is to identify the dimensions of intention of visitors to a cultural heritage site. This study aims to investigate the reasons why people visit the site where historical artifacts are located. It is hoped that such an investigation will contribute to the theoretical understanding of traditional tourism by highlighting the need to emphasize the relationship between tourist behavior and the place visited.

\section{REVIEW OF LITERATURE}

\subsection{Cultural Heritage Tourism}

Glason (1994) described the effects of cultural heritage tourism and management responses to Oxford through an overview of tourist characteristics. This article highlights the different perspectives and dimensions of the impact on the city's tourist potential. Peleggi (1996) examined the relevance of Thailand's heritage attractions to international and domestic tourism, including the theoretical implications of heritage sightseeing with the state tourism agency promoting heritage and authentic historical narratives. This research provided a number of characteristics, such as traditional villages, monuments, museums, and temples.

\subsection{Cultural Heritage Tourist Characteristics}

Silberberg (1995) identifies as a cultural / heritage traveler: making more money and spending more money while on vacation; Spend more time in the area during vacation; More educated than ordinary people; Females are more likely to be female than males, and are found in older age groups. Master and Prideaux (2000) examined the differences in Taiwanese cultural / heritage travelers' age, gender, occupation and past overseas travel, to determine whether demographic and travel characteristics influence responses to trait importance and satisfaction levels. Travelers visiting a South Wales heritage site compared to the characteristics of Light (1996). In this study, tourists 'experiences are key features in motivating tourists to revisit. Lee (1999) investigated individuals 'trip characteristics (trip group types) and past experience of the destination. They analyzed the relationship between past experience and attachment to place. Kerstetter et al., (2001) investigated whether the types of heritage travelers differ based on socio-demographic characteristics. This study shows that traditional tourists tend to stay longer, spend more per trip, are more educated and have higher average annual income than regular travelers. 
For this study, two characteristics were added to the Theory of Planned Behavior (TPB) model.1. A past behavioral attitude; Involvement in the trip.

\subsection{Past Behavior (PB)}

In social research, Quellet et., al (1998), and Sonmez et.,al (1998) highlighted that the past relational behavior can be analysed from present behavior and future behavior. The most important reason for this is that people likely to maintain persistence and value consistency. Henceforth past behavior is added into the TPB model to serve the purpose of behavior.

\subsection{Tour Involvement (TI)}

The theory of tour involvement can be found from previous research of consumer behavior (Flynn et.,al 1993; McIntyre, 1989) and entertainment, leisure and tourism (Havitz and DeManche, 1997; Park et al., 2002). Engaging here indicates the level of importance, interest or happiness attached to the cultural tour by the traveler. Cultural Heritage Site Tour can be considered as a kind of cultural tour. Individuals who involve more cultural travel during travel decision making may find that they pay more attention to cultural heritage sites.

Hence, this study is carried out to explore whether the modified TPB model predicts the purpose of visitors to cultural heritage sites.

\section{RESEARCH METHODOLOGY}

\subsection{Measurement Scales}

Part A The socio-demographic items were measured using nominal scales.

Part B The questions was designed to collect information on lifestyle measures and activity level preferences with 5point Likert scales ranging from most important (5) to least important (1).

Part C Tourists Behavior: In the context of the theory (TPB), the information on visitors' perception toward cultural heritage sites, subjective norms (data on information sources and reference groups), perceived control factors which may assist travel, past behavioural aspect of cultural heritage sites visit, and tour involvement which shows the importance and enjoyment of cultural tours was collected through designed questionnaire. From the literature review and relevant theories, the measurement scales for this study were measured.

Part D: the information on visitors' intention to visit cultural heritage sites was collected through designed questionnaire

\subsection{Sampling and data collection}

This study has a self-administered survey method and face-to-face interviews personally administered surveys with the selected tourism stakeholders (government tourism officials and private sector agents) in Tamilnadu particularly in Rameshwaram. The sample size is 420. Convenience sampling method was adopted from identified and independent sample frames to collect quantitative data from the respondents.

\subsection{Conceptual Framework}

The proposed structural model (Fig.1) was tested in this research of Tourists' Intention (INT) to visit the cultural places as they relate to Attitude of the visitors' (A), Subjective Norm (SN), Perceived Control (PC), with the new constructs of Past Behavior (PB) and Tour Involvement (TI).

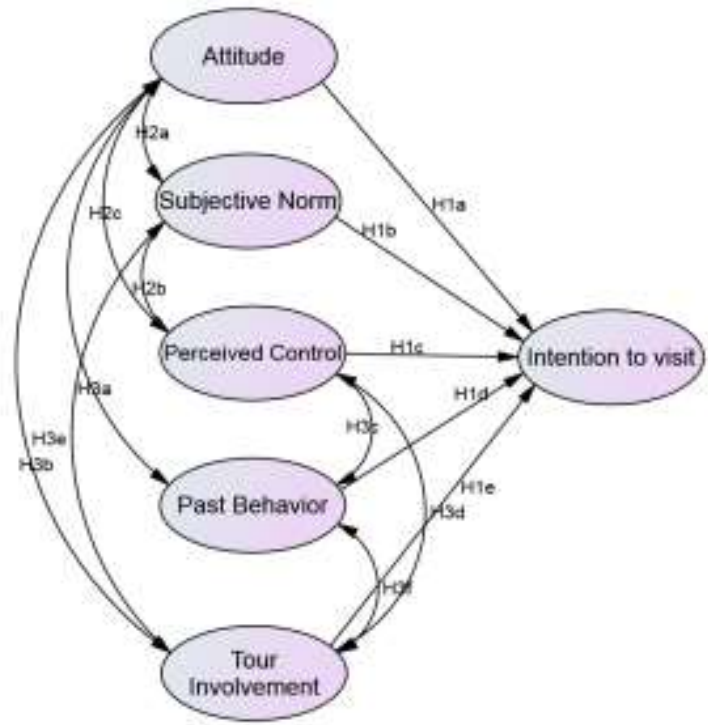

Fig 1: Conceptual model

\subsection{Data Analysis}

Data was analysed in two stages.

1) Exploratory Factor Analysis (EFA) was used for data reduction

2) A Confirmatory Factor Analysis (CFA) was used to confirm the factor structure of TPB.

\section{ANALYSIS AND FINDINGS \& RESULTS}

\subsection{Exploratory Factor Analysis (EFA) for Intention to} visit

The measurement scale for planned behavior constructs consisted of 15 items. Factor analysis had been applied on these 15 items to find the primary factors, and latent root criterion (eigenvalue) value of above 1.0 (Petty, 1989) and a factor loading of 0.40. EFA was performed on the sample using the 15 variables related to planned behavior. From EFA, five factors were extracted accounting for 63.8 percent of the total variance explained. The 14 items loaded well according to the standard value (Factor loadings $>0.4$ ). One item, namely "Tour to Rameshwaram is inexpensive" did not load good (Factor loading 0.410) on any of the factors. Table 1 shows the factor loadings for Behaviour constructs. Confirmatory factor analysis (CFA) loadings also suggest that 14 items confirmed with the factors extracted from EFA. One item namely "Tour to Rameshwaram is inexpensive (TB7)' was not confirmed and it was removed. 
Table 1 Rotated factor matrix for Behaviour constructs

\begin{tabular}{|c|c|c|c|c|c|c|c|}
\hline Factors & Factors & Measurement items & \multicolumn{5}{|c|}{ Factor loadings } \\
\hline \multirow[t]{3}{*}{ Attitude (A) } & TB1 & $\begin{array}{l}\text { More preference to heritage sites than other } \\
\text { sites }\end{array}$ & $84^{.7}$ & & & & \\
\hline & TB2 & Visiting heritage sites are sacred & $62^{.7}$ & & & & \\
\hline & TB3 & Attitude towards Rameshwaram is good & $84^{.6}$ & & & & \\
\hline \multirow[t]{3}{*}{$\begin{array}{l}\text { Subjective } \\
\text { Norms (SN) } \\
\end{array}$} & TB4 & $\begin{array}{l}\text { Media influenced you to come here(TV, } \\
\text { internet) }\end{array}$ & & $52^{.8}$ & & & \\
\hline & TB5 & Indian tourist agencies guided you here & & $23^{.8}$ & & & \\
\hline & TB6 & $\begin{array}{l}\text { Word of mouth created an intention to come } \\
\text { here }\end{array}$ & & $13^{.8}$ & & & \\
\hline \multirow[t]{3}{*}{$\begin{array}{c}\text { Perceived } \\
\text { Control (PC) }\end{array}$} & TB7 & Tour to Rameshwaram is inexpensive & & & 10 & & \\
\hline & TB8 & Infrastructural facilities is good & & & $90^{.7}$ & & \\
\hline & TB9 & Can adapt to the climatic conditions here & & & $75^{.7}$ & & \\
\hline \multirow[t]{3}{*}{$\begin{array}{c}\text { Past } \\
\text { Behaviour } \\
\text { (PB) }\end{array}$} & TB10 & Your previous visit attracts you & & & & $13^{.8}$ & \\
\hline & TB11 & Feels worth to visit this site & & & & $90^{.7}$ & \\
\hline & TB12 & You have good opinion about Rameshwaram & & & & $75^{.7}$ & \\
\hline \multirow[t]{3}{*}{$\begin{array}{c}\text { Tour } \\
\text { Involvement(TI) }\end{array}$} & TB13 & Eager to know about various cultures & & & & & $90^{.6}$ \\
\hline & TB14 & Visiting heritage sites are interesting & & & & & 59 \\
\hline & TB15 & Trip to heritage sites are more informative & & & & & $41^{.6}$ \\
\hline
\end{tabular}

The five factors are labeled as below.

Factor 1 named "ATTITUDE (A)" accounted for 21.649 percent of the deviations with 3 elements. The highest stress item was "Preferential than other heritage sites," followed by "Visiting heritage sites is sacred" and "Attitude to Rameshwaram is good."

Factor 2, "SUBJECTIVE NORMS (SN)", accounted for 19.292 percent of the deviations with 3 elements. The most charged item was "Media Made You Come Here (TV, Internet)", followed by "Indian Travel Agents Who Led You Here".

Factor 3, "PERCEIVED CONTROL (PC)", explained 8.986 percent of the deviations with 3 elements. The element with the highest load in this component is "Infrastructures are good," followed by "Can adapt to climatic conditions." The load on the factor "Tour to Rameshwaram is favorable" was 0.410 and has minimal impact on behavior.

Factor 4: "CONDUCT IN THE PAST (PAST BEHAVIOR, PB) accounted for 20.714 percent of the deviations with 3 elements. The statement with the highest load was "Your previous visit attracts you, followed by"
Recommends to visit this website "and" You have a good opinion of Rameshwaram ".

Factor 5, "TOUR INVOLVEMENT (TI)", accounted for 20.714 percent of the deviations with 3 positions. The highest loaded statement was "Inquisitive about Different Cultures," followed by "Visits to Cultural Sites are Interesting," and "Travel to Cultural Sites are more Informative."

\subsection{MEASUREMENT MODEL}

\subsubsection{Confirmatory Factor Analysis (CFA)}

The five factors of Tourist Intention (INT) to visit the site again identified through exploratory factor analysis, ATTITUDE of the Visitors'(A), SUBJECTIVE NORMS (SN), PERCEIVED CONTROL (PC), PAST BEHAVIOUR in the previous visit(PB), TOUR INVOLVEMENT of the visitors (TI) were then tested for Confirmatory Factor Analysis (CFA) to find out the factor loadings of the items. The confirmatory factor analysis was executed using AMOS 21. The standardized CFA - model 1 was done with five 
factors of tourist intention to visit the site again and illustrated in Figure 2.

Model 1 presented some high correlations between error terms, as specified by the modification indices. Consequently, the model shown a mediocre fit and needed modification. Therefore, initial model-1 was modified based on Squared multiple indices (SMC) and modification indices
(M.I). The results (Table 2) of the initial assessment of the CFA (model -1) of the tourist intention constructs were not up to the standard value and not accepted since there was a Chi-square value of 206.712 with 104 degrees of freedom (p $<.001)$ and a Root Mean Square Error of Approximation (RMSEA) of 0.056 .

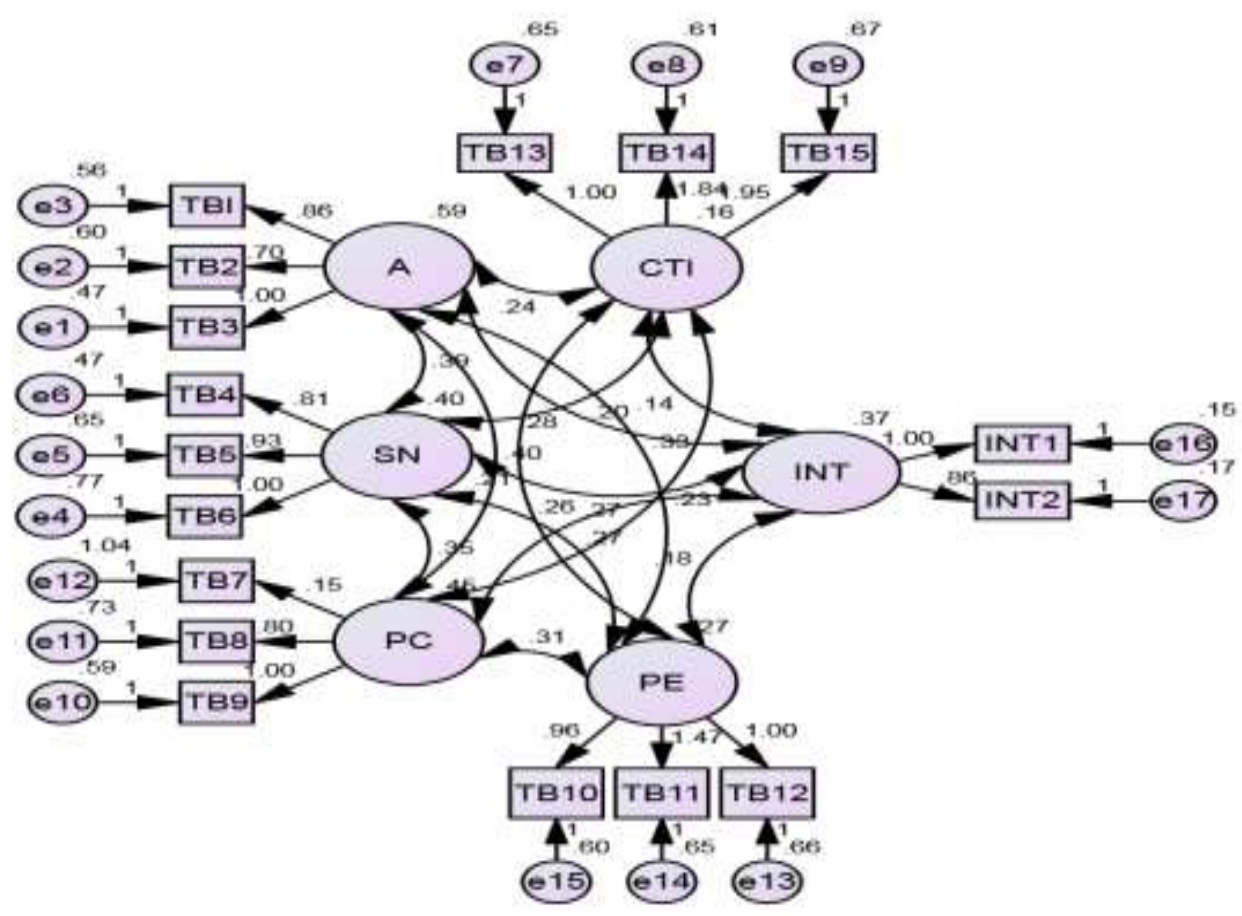

Data analysis and results

Figure 2 Measurement Model 1

Table 2 Model Fit Indices - Measurement model CFA (Model 1)

\begin{tabular}{|l|l|l|}
\hline Model Fit indices & Model -1 & Standardized Values \\
\hline Absolute Fit Measures & 206.712 & \\
Chi-square of estimate model & 104 & $\leq 3.00$ (Hair et al., 1998) good fit \\
df & 1.988 & $\mathrm{P}<0.05$ \\
(X $\mathbf{2} / \mathbf{d})$ & 0.000 & $\geq 0.90$ (Byrne, 2001) best fit \\
Probability & 0.928 & $<1.0$ (Hu and Bentler, 1999) best fit \\
\hline Goodness-of-fit index (GFI) & 0.045 & $\leq .06$ (Hu and Bentler, 1999) best fit \\
\hline R0ot mean square residual (RMR) & 0.056 & $\geq .80$ (Hair et al., 1998) best fit \\
\hline Root mean square error of approximation (RMSEA) & $\geq .90$ (Bentler, 1992) best fit \\
\hline Incremental Fit Measures & 0.894 & \\
\hline Adjusted goodness-of-fit index (AGFI) & 0.933 & \\
\hline Parsimonious Fit Measures & & \\
\hline Comparative fit index (CFI) & & \\
\hline
\end{tabular}

Note: All t-value were significant @ 5\%

$\mathrm{X}^{2}=$ Chi-Square; $\mathbf{d f}=$ degrees of freedom; GFI = goodness-of-fit index; AGFI = adjusted goodness-of-fit; 


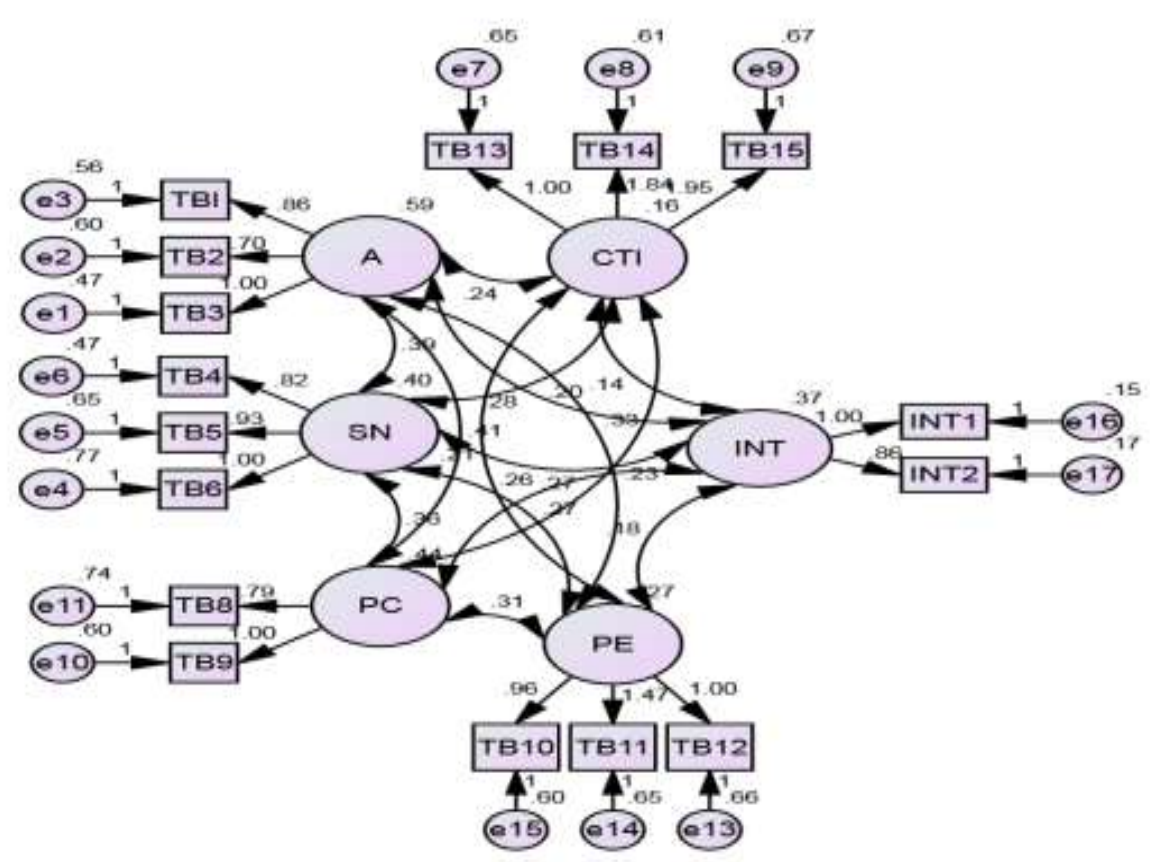

Figure 3 Measurement Model 2

Model-2 was arrived after excluding the variable TB7 with each of these results built on the strength of association of that item with other items. Figure 3 and Table 3 shows the better fitting model with the deleted items.

The standardized CFA - model 2 solution was highly acceptable (Table 3). However, under these circumstances, the standardized CFA - model 2 shown a significantly more satisfactory goodness-of-fit (Table 3) than the model-1 as per the chi-square difference test, and minimizing the set of out-of-range parameter values.
Model-2 was greatly acceptable according to the estimates of goodness-of-fit for the revised model (Table 3 ). First the effect of dividing the chi-square value (CMIN) by the degrees of freedom (DF) was examined. This results in a ratio (CMIN/DF) with a perfect value of 1.987 which is in the $0-3$ range and is significant at $5 \%(\mathrm{p}=.05)$. The RMSEA value is 0.05 . The values less than 0.06 shows good fit $(\mathrm{Hu}$ and Bentler, 1999). From this measure, the model shows an acceptable fit. The other fit indices also indicated a mediocre fit (Table 3 for acceptance limit for model fit indices)

Table 3 Model Fit Indices - Measurement model CFA (Model 2)

\begin{tabular}{|l|l|l|}
\hline Model Fit indices & Model -2 & Standardised Values \\
\hline $\begin{array}{l}\text { Absolute Fit Measures } \\
\text { Chi-square of estimate model } \\
\text { (X } \mathbf{2} / \text { DF }) \\
\text { Probability }\end{array}$ & $\begin{array}{l}176.836 \\
89 \\
1.987 \\
0.000\end{array}$ & $\begin{array}{l}\leq 3.00 \text { (Hair } \text { et al., 1998) good fit } \\
\mathrm{P}<0.05\end{array}$ \\
\hline Goodness-of-fit index (GFI) & 0.934 & $\geq 0.90$ (Byrne, 2001) best fit \\
\hline Root mean square residual (RMR) & 0.042 & $<1$ (Hu and Bentler, 1999) good fit \\
\hline Root mean square error of approximation(RMSEA) & 0.05 & $\leq 0.06$ (Hu and Bentler, 1999) good fit \\
\hline $\begin{array}{l}\text { Incremental Fit Measures } \\
\text { Adjusted goodness-of-fit index (AGFI) }\end{array}$ & 0.899 & $\geq 0.80$ (Hair et al., 1998)best fit \\
\hline Parsimonious Fit Measures & 0.933 & $\geq 0.90$ (Bentler, 1992)good fit \\
\hline Comparative fit index (CFI) & & \\
\hline
\end{tabular}

Note: All t-value were significant at 5\% level

$\mathrm{X}^{2}=$ Chi-Square; $\mathbf{d f}=$ degrees of freedom; GFI = goodness-of-fit index; AGFI = adjusted goodness-of-fit; CFI = comparative fit index; $R M R=$ Root Mean Square; RMSEA = root mean square error of approximation 
Table 4. - Standardized regression weight factor loadings -Model 2

\begin{tabular}{|c|c|c|c|c|c|c|}
\hline Item A & Direction & Item B & B Estimate & S.E. & C.R. & $\mathbf{P}$ \\
\hline TB3 & <--- & A & .746 & & & \\
\hline TB2 & <--- & A & .567 & .079 & 8.815 & $* * *$ \\
\hline TB1 & <--- & A & .662 & .085 & 10.137 & $* * *$ \\
\hline TB6 & <--- & $\mathrm{SN}$ & .587 & & & \\
\hline TB5 & <--- & SN & .591 & .118 & 7.837 & $* * *$ \\
\hline TB4 & $<--$ & $\mathrm{SN}$ & .604 & .102 & 7.958 & $* * *$ \\
\hline TB13 & $<--$ & CTI & .447 & & & \\
\hline TB14 & $<--$ & CTI & .688 & .262 & 7.034 & $* * *$ \\
\hline TB15 & $<---$ & CTI & .695 & .277 & 7.060 & $* * *$ \\
\hline TB9 & <--- & $\mathrm{PC}$ & .652 & & & \\
\hline TB8 & <--- & PC & .521 & .105 & 7.578 & $* * *$ \\
\hline TB12 & <--- & PB & .537 & & & \\
\hline TB11 & <--- & PB & .686 & .171 & 8.617 & $* * *$ \\
\hline TB10 & $<--$ & PB & .541 & .129 & 7.426 & $* * *$ \\
\hline INT1 & $<---$ & INT & .843 & & & \\
\hline INT2 & <--- & INT & .788 & .077 & 11.170 & $* * *$ \\
\hline
\end{tabular}

Standard regression weights have also been examined for testing the model fit. Table 4 shows, the latent variable 1 behavior (a) was significantly related with all 3 items, the latent variable 2 subjective norms ( $\mathrm{SN}$ ) was significantly associated with the 3 factors, and the latent variable 4 Past Behavior (PB) was significantly associated with the 3 items and the latent variable 5 Tour involvement (TI) is significantly associated with 3 objects. Only the Perceived Control (PC), latent variable 3 was significantly associated with 2 items. The TB7 item is not significant and will be removed. The factor loadings are larger than their standard errors (table 4).

\section{DISCUSSIONS AND CONCLUSIONS}

Exploratory factor analysis (EFA) was performed to construct a tourist objective (TI) to compress the measurement scales. Second, COnfirmatry factor analysis (CFA) was executed to enhance the relationships of the observed indicators to the constructs. The five structures of the TPB, each containing 3 items, produced a Cronbach's coefficient alpha of 0.859 . Reliability exceeds the recommended level of 0.7 (Hair et al., 1989). Hence this value shows the scale of the measure is reliable in modeling the intent of visitors to a cultural heritage site.

The EFA was modeled using 15 variables related to planned behavior. By EFA, the five factors accounted for 63.8 percent of the total variance explained. 14 items were loaded correctly (factor loading $>0.4$ ). An item called "Tour to Rameshwaram is cheap" did not load well on any of the factors (factor loading 0.410). Confirmatory factor analysis (CFA) loadings indicate that 14 items are confirmed with extracts from the EFA. "An item called Tour to Rameshwaram is cheap (TB7) link has not been confirmed and has been removed.

The study enhances tourism literature by presenting a conceptual framework (model) that describes the relationship between (1) attitude (A), (2) subjective Norm (SN), (3) perceived control (PC), (4) past behavior (PB)), (5) Travel Involvement (TI) and (6) Tourist Intent (INT) to Visit Heritage Places in the framework of Planned Behavior Theory (TPB). This conceptual model provides new insights into cultural heritage tourism research

\section{REFERENCES}

1. Byrne, J. M. (2oo1). Structural equation modeling with AMOS: basic concepts, applications and programming. London: Companions of Lawrence Erlbaum.

2. Bentler, P.M. (1992). Model fit on covariance and method bulletin. Psychological Bulletin, 112, 400-404.

3. Espelt, n. G., and Benito, J. A. D. (2006). Visitor behavior in traditional cities: The case of Girona. Journal of Travel Research, 44 (4), 442-448.

4. Flynn, L.R. \& Goldsmith, R.E. (1993). Personal involvement in marketing is an inventory application. Psychology and Marketing, 10, 357-366.

5. Glason, J. (1994). Oxford: Heritage City Under Pressure. Tourism Management, 15 (2), 137-144.

6. Grimwade, G. \& Carter, b. (2000). Managing small heritage sites with definition and community involvement. International Journal of Heritage Studies, 6 (1), 33-48.

7. Herbert, d. (2001). Literary sites, tourism and heritage experience. Annals of Tourism Research, 28 (2), 312 333.

8. Hair, Anderson, R.. E., Tatham, R L., and Black, W. C. (1998). Multivariate Data Analysis (5th Edition). London: Prentice-Hall International.

9. Havitz, M. and DeManche, (1997). Proposals to examine participation in entertainment and tourism scenarios. Leisure Science, 12, 179-195.

10. Flower, L.T. \& Bentler, P.M. (1999). Cutoff criteria for fit indices in covariance structure analysis: New criteria versus conventional models Structural equation modeling, 6 (1), 1-55.

Published By: 
11. Flower, L.T. \& Bentler, P.M. (1999). Cutoff criteria for fit indices in covariance structure analysis: New criteria versus conventional models Structural equation modeling, 6 (1), 1-55.

12. Johnson, n. C. (1999). Shaping the past: the time, place and politics of Ireland's traditional tourism. Political Geography, 187-207. 